\title{
Optimising Ductility of Poly(Lactic Acid)/Poly(Butylene Adipate-co- Terephthalate) Blends Through Co-continuous Phase Morphology
}

\author{
Yixin Deng ${ }^{1} \cdot$ Changyi Yu ${ }^{1} \cdot$ Peangpatu Wongwiwattana ${ }^{1} \cdot$ Noreen L. Thomas $^{1}$
}

Published online: 1 June 2018

(c) The Author(s) 2018

\section{Abstract}

This paper examines the effect of the melt viscosities of the two component polymers on the morphology and mechanical properties of a series of biodegradable polymer blends. Melt blended compounds of poly(lactic acid) (PLA) and poly(butylene adipate-co-terephthalate) (PBAT) are prepared and their melt viscosities, thermal properties, crystallinity, mechanical properties and phase morphology are investigated. From the relative melt viscosities of PLA and PBAT in the processing regime used in the study, it is possible to calculate the volume fraction at which a co-continuous phase structure is formed. The predicted value is $19 \mathrm{wt} \%$ of PBAT and this value is verified by the results of mechanical properties, where results for elongation-to-break show a dramatic rise from around $10 \%$ up to $300 \%$ in the composition range between 10 and $20 \mathrm{wt} \%$ of PBAT. The co-continuous phase structure is also validated by scanning electron microscopy.

\section{Graphical Abstract}

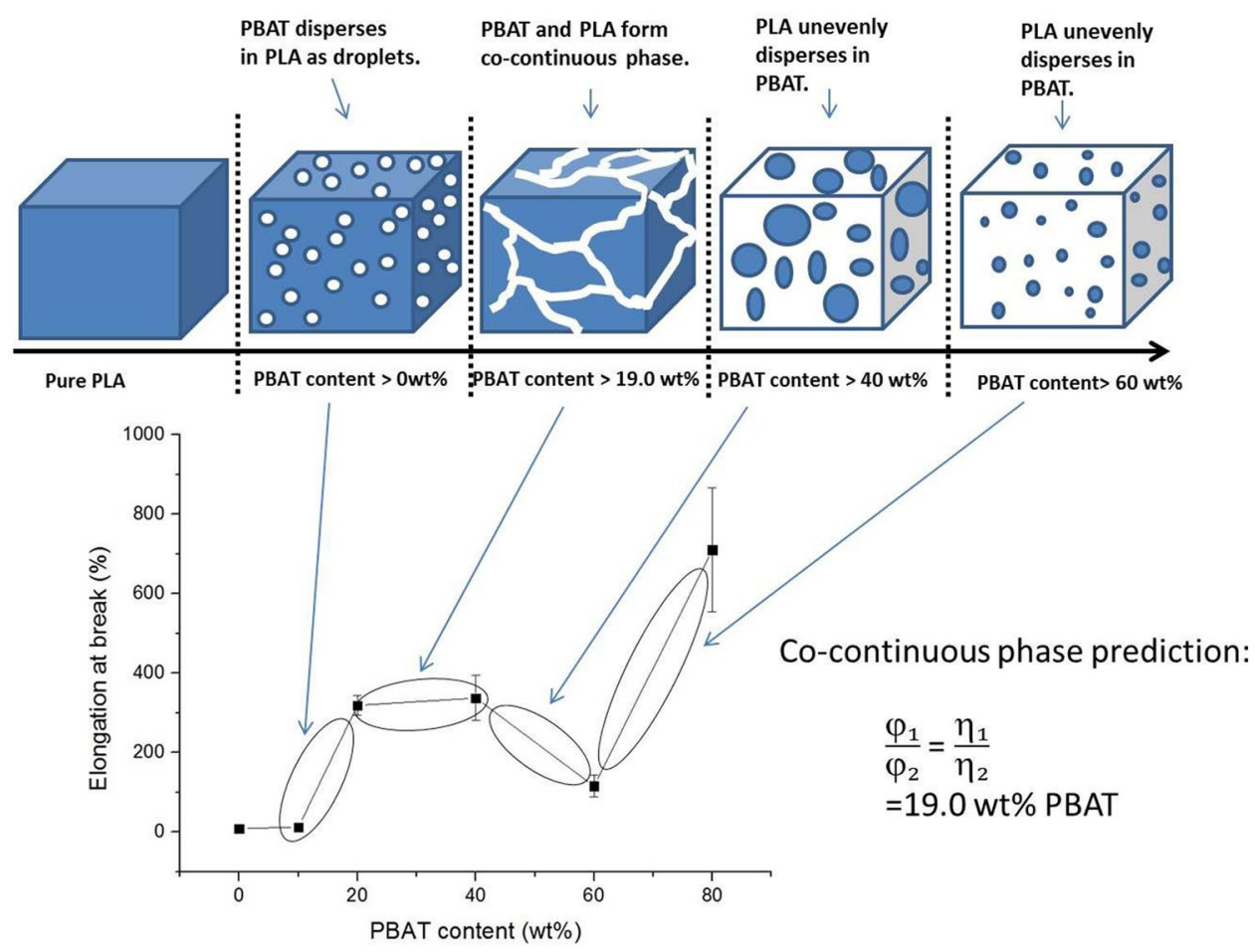

Keywords Poly $($ lactic acid $) \cdot$ Poly (butylene adipate-co-terephthalate $) \cdot$ Co-continuous phase $\cdot$ Biodegradable $\cdot$ Blends

Extended author information available on the last page of the article 


\section{Introduction}

Recently there has been a huge growth in the development of bio-degradable plastics to reduce the environmental impact of the disposal of conventional oil-based plastics [1-3]. Those bio-degradable polymers that are also bio-based, i.e. derived from renewable feedstocks, have the added advantage of a reduced carbon footprint. In the growing bio-based economy, poly(lactic acid) (PLA) is one of the most prominent thermoplastics [4]. It is used in packaging and other short-life disposable applications, as well as in biomedical products because of its biocompatibility.

The molecular structure of PLA is shown in Fig. 1. Lactic acid is obtained by fermentation of starch that comes from maize or corn. The polymer is produced via ring-opening polymerisation of the lactide, which is a cyclic dimer comprising two lactic acid molecules [5]. The extent to which PLA will crystallise is highly dependent on the amount of L-and D-lactic acid in the polymer. Higher chain symmetry, and therefore higher crystallinity, occurs in the more optically pure forms. Compared with other biodegradable polymers, PLA is relatively cheap because of its lower cost polymerisation method. However PLA has a glass transition of about $\left(57^{\circ} \mathrm{C}\right)$ and so it is rigid and quite brittle at room temperature [5]. This disadvantage significantly limits the application of PLA in ductile products.

To toughen PLA, a number of methods such as melt blending, plasticization, copolymerization and incorporation of impact modifiers have been applied [6, 7]. Melt blending with ductile polymers is an effective and low cost way to enhance the toughness of PLA [7]. It is a process of physical blending in the melt to mix different polymers without chemical reactions taking place. Obviously, to maintain biodegradability, the blending component used to toughen PLA must be not only ductile but also biodegradable.

Poly(butylene adipate-co-terephthalate) (PBAT) is a ductile and biodegradable polymer which has good processability and

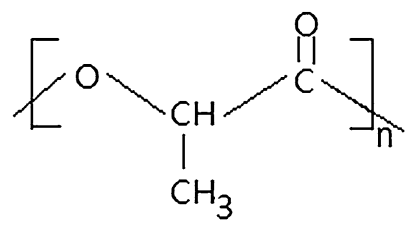

Fig. 1 Molecular structure of PLA hydrophilic properties [2]. The glass transition temperature $\left(\mathrm{T}_{\mathrm{g}}\right)$ of PBAT is about $-30{ }^{\circ} \mathrm{C}$, which indicates that it is very ductile at room temperature. Figure 2 is the molecular structure of PBAT. It contains two different co-monomers: one is butylene terephthalate, which is derived from terephthalic acid and 1,4-butanediol, and the other co-monomer is butylene adipate, which is ductile and is produced from adipic acid and 1,4-butanediol [8]. PBAT can be blended with other polymers to enhance their performance [9]. It is regarded as a good candidate for toughening PLA because of its low elastic modulus and high elongation-to-break ( $>500 \%)$, which are similar to the performance of a thermoplastic elastomer, and because of its complementarity with PLA [10].

There are a number of interesting studies in the literature reporting on PLA/PBAT blends. An important factor that determines the success of melt blending of two polymers is their mutual miscibility. In the case of melt blending of two bio-degradable polyesters, there would be expected to be attractions between polar groups leading to stronger interactions and hence some miscibility [7, 11]. Liu et al. [12] have reported that the solubility parameters, $\delta$, of poly(L-lactide) (PLLA) and PBAT are 19.70 and $19.83 \mathrm{~J}^{0.5} / \mathrm{cm}^{1.5}$ respectively. The closeness of these values suggests that these two polymers are potentially miscible. In their investigation of miscibility by dynamic mechanical analysis (DMA), thermal mechanical analysis (TMA), differential scanning calorimetry (DSC) and atomic force microscopy (AFM), these authors concluded that the blend with $25 \%$ PBAT exhibited the highest miscibility. Yeh et al. [13] reported that PBAT molecules are miscible with PLA molecules up to $2.5 \mathrm{wt} \%$ addition of PBAT but above this amount phase separated droplets can be distinguished. Also phase separated 'sea-island' morphologies are reported in other studies $[14,15]$ indicating that miscibility between PLA and PBAT is limited.

Several papers have reported on mechanical properties, morphology and crystallinity of PLA/PBAT blends. Jiang et al. [16] found that elongation-to-break of PBAT/PLA blends increased to $100 \%$ at an addition level of $5 \mathrm{wt} \%$ PBAT and to $200 \%$ at an addition level of $20 \mathrm{wt} \%$ PBAT. They suggested that PBAT was evenly dispersed in the form of domains with a size of around $300 \mathrm{~nm}$ within the PLA matrix. They attributed the large improvement in ductility to rubber-toughening and a debonding-initiated shear yield mechanism. Chiu et al. [15] found a two-phase sea-island morphology in PBAT/PLA bends. They obtained the best tensile and impact strength in the blend containing a PBAT content of $70 \mathrm{wt} \%$. Farselti et al. [14] found that elongation-to-break increased from $3 \%$ (pure

Fig. 2 Molecular structure of PBAT

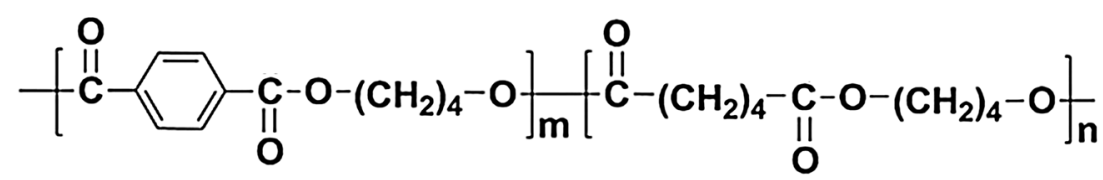


PLA) to $45 \%$ at a PLA/PBAT blend ratio of $80 / 20$, which they attributed to a rubber toughening effect because of the small spherical inclusions of PBAT in the PLA matrix. They also found an increase in the critical strain energy release rate $\left(\mathrm{G}_{\mathrm{IC}}\right)$ with increasing PBAT content, which they ascribed to a debonding effect between the phases. Xiao et al. [17] investigated the crystallization behaviour of PLA/PBAT blends and found that the crystallinity of PLA was markedly increased in the presence of PBAT but that the crystallization mechanism remained unchanged. $\mathrm{Li}$ et al. [18] observed three distinct morphologies for PBAT/PLA blends in their SEM images: spherical droplets (PBAT $<20 \mathrm{wt} \%$ ), elongated fibrous structures $(20 \mathrm{wt} \%<$ PBAT $<50 \mathrm{wt} \%)$ and a co-continuous structure $(50 \mathrm{wt} \%<\mathrm{PBAT}<70 \mathrm{wt} \%)$. When the PBAT content reached $>70 \mathrm{wt} \%$, the morphology reverted to droplets again but with PLA now dispersed in a matrix of PBAT.

The properties of immiscible melt blended polymers will be dependent on the morphology produced, and this obviously depends on the concentration ratio of the two polymers as well as the processing history, which will determine the melt Rheology of the blend. It is most often the case that the major component will form the continuous phase with the minor component dispersed in it as spherical droplets, although elongated fibrils may occur depending on the flow conditions. Existence of two continuous phases as an interpenetrating network structure will occur near the phase inversion point and this region of dual phase continuity of two polymers gives a unique combination of their properties.

It is generally accepted that as well as the relative volume fractions of the two polymers, the ratio of their melt viscosities is important in predicting co-continuous phase behaviour [19, 20]. Paul and Barlow [21] and Jordhamo et al. [22] proposed a semi-empirical equation for predicting dual phase continuity in polymer blends and simultaneous interpenetrating networks, which is given by Eq. 1 .

$\frac{\varphi_{1}}{\varphi_{2}}=\frac{\eta_{1}}{\eta_{2}}$

In this equation, $\varphi_{1}$ and $\varphi_{2}$ are the volume fractions of polymer blend components 1 and 2 , and $\eta_{1}$ and $\eta_{2}$ are their respective shear viscosities at the relevant processing temperature and shear rate. This equation predicts that if $\eta_{1} /$ $\eta_{2}>\varphi_{1} / \varphi_{2}$, then component 2 will be the continuous phase with component 1 forming the dispersed phase. However, when $\eta_{1} / \eta_{2}=\varphi_{1} / \varphi_{2}$, then components 1 and 2 will form a co-continuous phase.

A further model based on the ratio of melt viscosities was developed by Metelkin and Blekht [23, 24], which is represented in Eqs. (2) and (3), where $\lambda=\eta_{1} / \eta_{2}$ and $\varphi 2$ is the inversion point of component 2.

$\varphi_{2}=\frac{1}{1+\lambda F(\lambda)}$
$F(\lambda)=1+2.25 \log \lambda+1.81(\log \lambda)^{2}$

A different model for the prediction of co-continuous phase morphologies in polymer blends was developed by Willemse et al. [25]. This model was centred on the geometric requirements for co-continuous structures. It results in an equation [Eq. (4)] describing the critical volume fraction of the minor phase for complete co-continuity $\left(\varphi_{\mathrm{cc}}\right)$ as a function of the matrix viscosity $\left(\eta_{\mathrm{m}}\right)$, interfacial tension $(\sigma)$, shear rate $(\dot{\gamma})$ and phase dimensions $\left(\mathrm{R}_{0}\right.$ being the radius of a spherical particle as it deforms into a long cylinder).

$\frac{1}{\varphi_{c c}}=1.38+0.0213\left(\frac{\eta_{m} \dot{\gamma}}{\sigma} R_{0}\right)^{4.2}$

This model predicts a range of compositions within which fully co-continuous structures can exist. The critical volume fraction is not dependent on the viscosity of the dispersed phase, and so these authors concluded that the relationship between the volume fraction at phase inversion and the viscosity ratio of the blend components is not generally valid.

Although PLA is often blended with other biodegradable polymers, there have been very few investigations into predicting a co-continuous phase structure for these systems. Wu et al. [26] studied the phase behaviour of polylactide/poly(caprolactone) (PLA/PCL) blends and the viscoelastic response of these materials. For this system they proposed that the elasticity ratio had an important effect on the phase inversion behaviour, in addition to viscosity, because PLA/PCL blends have such a high viscosity ratio. In a recent paper, Deng and Thomas [27] investigated synergistic effects of blending PLA with poly(butylene succinate) (PBS). In this system there was found to be a dramatic improvement in ductility with as little as $10 \mathrm{wt} \%$ of PBS added. This was shown to be due to a co-continuous phase morphology, which could be explained by the relative viscosities of the components.

As discussed above, a number of researchers have blended PBAT with PLA to achieve better performance, particularly with respect to mechanical properties. However, there has been no investigation into producing a cocontinuous phase structure in a blend of PLA and PBAT. The aim of this paper is to verify whether PBAT/PLA blends can form a co-continuous phase as predicted by the viscosity ratio model of Eq. (1) and to exam the effect of the co-continuous phase on mechanical properties. 


\section{Experimental}

\section{Materials}

Poly(lactic acid) (PLA) (Ingeo ${ }^{\mathrm{TM}}$ 4032D) was procured from Natureworks LLC (Minnetonka, MN, USA). This grade of PLA has an L-lactide content of $98.6 \mathrm{w} \%$ and is a crystallisable grade of PLA with a melting point in the range $160-180^{\circ} \mathrm{C}$. It has a density of $1.24 \mathrm{~g} \mathrm{~cm}^{-3}$. Its weight average molecular weight $\left(\mathrm{M}_{\mathrm{w}}\right)$ was determined as $94 \times 10^{3} \mathrm{~g}$ $\mathrm{mol}^{-3}$ from gel permeation chromatography (GPC) measurements. Poly(butylene adipate-co-terephthalate) (PBAT, biosafe 2003) with a glass transition temperature of $-34{ }^{\circ} \mathrm{C}$ and a melting point around $109^{\circ} \mathrm{C}$ was obtained from Xinfu Pharmaceutical Co., Ltd, China.

\section{Sample Preparation}

Melt blending of PBAT with PLA was carried out at a range of composition ratios (PBAT/PLA by weight: 0/100, 10/90, 20/80, 40/60, 50/50, 60/40, 80/20 and 100/0). Absorbed moisture was first removed by drying the two polymers in a vacuum oven for $24 \mathrm{~h}$ at a temperature of $65^{\circ} \mathrm{C}$. After that they were melt blended in a Haake Rheomix OS counterrotating mixer, which promotes dispersive and distributive mixing. The total sample weight in the mixing chamber was $58 \mathrm{~g}$ and the mixing process was carried out at $175^{\circ} \mathrm{C}$ for $10 \mathrm{~min}$ at a rotor speed of $60 \mathrm{rpm}$. Neat PBAT and PLA were also melt processed in the Haake at the same condition as the blends so that all samples had the same thermomechanical history. The polymer samples from the mixer were then compression moulded into sheets. This was done by preheating the polymer for $15 \mathrm{~min}$ and compressing it into a sheet for 3 min under a pressure of 15 tons (creating a pressure on the sheet of $11.3 \mathrm{MPa}$ ) at a temperature of $180{ }^{\circ} \mathrm{C}$, followed by cooling to room temperature over a period of 3 min under a pressure of 5 tons (creating a pressure on the sheet of 3.8 MPa). The sheets were of thickness $1 \pm 0.10 \mathrm{~mm}$ and from these tensile bars were cut.

\section{Characterization and Testing}

\section{Capillary Rheometry}

A flowmaster (ROSAND) capillary rheometer was used to determine the shear viscosities of both PLA and PBAT at $175^{\circ} \mathrm{C}$. This test was carried out on pristine samples of the two polymers. The twin-bore barrel contained a die of length/diameter ratio of 16 and a 'zero length' die to generate a Bagley correction and hence eliminate pressure endeffects. Pressure was measured at various ram velocities.
Ram velocities for PLA were varied between 1000 and $200 \mathrm{~mm} \mathrm{~s}^{-1}$ and those of PBAT between 2000 and $800 \mathrm{~mm}$ $\mathrm{s}^{-1}$. Higher velocities were required for PBAT because of its low melt viscosity.

\section{Differential Scanning Calorimetry (DSC)}

DSC was used to investigate the melting and crystallization behaviour of PBAT/PLA blends. Measurements were conducted using a DSC Q200 (TA Instruments, USA) fitted with an auto-sampler and mechanical cooler. Samples of approximately $10-15 \mathrm{mg}$ were cut from the polymer sheet and sealed in aluminium pans before being loaded into the chamber. Specimens were heated in a nitrogen atmosphere from 20 to $200{ }^{\circ} \mathrm{C}$ at a heating rate of $10{ }^{\circ} \mathrm{C} \mathrm{min}{ }^{-1}$. For every composition, at least three specimens were tested to calculate the average value and standard deviation.

The amount of overall crystallinity, $X_{c}$, was calculated using Eq. 5.

$X_{C}=\left(\frac{\Delta H_{m}-\Delta H_{c}}{\Delta H_{100} \times W p}\right) \times 100 \%$

where $\Delta H_{m}$ is the enthalpy of melting; $\Delta H_{c}$ is the enthalpy of cold crystallization; $\Delta H_{100}$ is the enthalpy of fusion for $100 \%$ crystalline polymer; and $\mathrm{W}_{\mathrm{p}}$ is the weight fraction of polymer. For PLA, $\Delta H_{100}=93 \mathrm{~J} / \mathrm{g}$ and for PBAT, $\Delta H_{100}=114 \mathrm{~J} / \mathrm{g}[8,17]$, although, being a random co-polymer, PBAT does not crystallize to a great extent.

\section{Optical Microscopy}

Optical microscopy was used to observe the morphology of the blends and hence to study the dispersion of the two components. The microscope used was a Leica ${ }^{\circledR}$ DMRX (Leica Microsystems Ltd, Germany) binocular transmitted light microscope. Specimens of roughly $10 \mu \mathrm{m}$ thickness were cut from the compression moulded sheets with a glass knife using a cryosectioning technique. The specimens were placed on a glass slide and covered with a glass slip. They were observed in bright field illumination at a magnification of $\times 400$.

\section{Scanning Electron Microscopy (SEM)}

The morphology of the fracture surfaces of the PBAT/PLA blends was examined using a scanning electron microscope equipped with a field emission gun (FEGSEM, LEO 1530 VP). The samples were gold coated before examination. The FEGSEM was operated at a voltage of $5 \mathrm{kV}$ at various magnification levels.

In addition, PBAT/PLA of compositions 20/80, 40/60, $60 / 40$ and 80/20 were immersed in acetone for $8 \mathrm{~h}$ with 
magnetic stirring to dissolve the PLA phase because acetone is a good solvent for PLA [28]. Then the residual blends were taken out of the solvent and examined using SEM. This process was carried out to etch the PLA from the surface and reveal the phase structure, as suggested by the work of Galloway and Macosko [29].

\section{Tensile Testing}

A universal testing machine (LLOYD Instruments) was used to determine the tensile properties of the samples. The compression moulded sheets were cut into dumbbell shapes with thickness of $1 \mathrm{~mm}$, a gauge length of $25 \mathrm{~mm}$ and width of $4 \mathrm{~mm}$. The crosshead speed used was $10 \mathrm{~mm} \mathrm{~min}^{-1}$. In order to determine the critical concentrations at which a co-continuous phase of PBAT/PLA was formed and subsequently disappeared, a range of compositions were tested. These included $0,2,4,6,8,10,12,14,16,18,20,40,50$, 60,80 and $100 \mathrm{wt} \%$ of PBAT. For each composition ratio, at least eight specimens were tested.

\section{Results and Discussion}

\section{Melt Rheology}

The shear viscosities of PLA and PBAT were measured by using capillary rheometry at $175^{\circ} \mathrm{C}$. The variation of the shear viscosities of PLA and PBAT with increasing shear strain rate is shown in Fig. 3. It is obvious from Fig. 3 that the melts of both PLA and PBAT are shear thinning fluids. To describe the relationship between shear viscosity and shear strain rate, the power law, shown in Eq. (6), was applied.

$\eta=\eta_{0} \dot{\gamma}^{(n-1)}$

In this equation, $\eta$ is shear viscosity; $\eta_{0}$ is the consistency index; $\dot{\gamma}$ is shear strain rate and $\mathrm{n}$ is the power law index.

Taking logarithms of both sides of Eq. (6) gives the relationship between shear viscosity and shear strain rate shown in Eq. (7). This is plotted in Fig. 3 to obtain the values of $\mathrm{n}$ and $\eta_{0}$.

$\log _{10}(\eta)=(n-1) \log _{10}(\dot{\gamma})+\log _{10}\left(\eta_{0}\right)$

The slope and intercept of PLA in Fig. 3 are -0.524 and 4.1455, so for PLA; $n=0.476, \eta_{0}=13,980, \eta_{\text {PLA }}=13,980$ $\dot{\gamma}^{-0.524}$. For PBAT, the slope from Fig. 3 is -0.282 and the intercept is 3.0806 and so the relevant parameters are $\mathrm{n}=0.718, \eta_{0}=1204$ and $\eta_{\text {PBAT }}=1204 \dot{\gamma}^{-0.282}$.

To transform the rotor speed of the Haake mixer to shear strain rate, the Newtonian equivalent expression [30], shown in Eq. (8), was applied.

$\dot{\Upsilon}=16 \pi N \frac{\beta^{2}}{\left(1+\beta^{2}\right)\left(\beta^{2}-1\right)} \approx \frac{2 \pi N}{\ln (\beta)}$

In Eq. (8), $\dot{Y}$ is the shear strain rate, $\mathrm{N}$ represents the rotor speed, $\beta$ is the value of the wall radius $\left(\mathrm{R}_{\mathrm{e}}\right)$ divided by the rotor radius $\left(\mathrm{R}_{1}\right)$. The rotor speed of the Haake mixer was $60 \mathrm{rpm}$, which means 60 revolutions per minute. The wall radius and rotor radius are 20 and $17.5 \mathrm{~mm}$. So the shear strain rate of the mixing process in the Haake mixer was calculated to be $47 \mathrm{~s}^{-1}$. By substituting a shear strain rate
Fig. 3 Shear strain rate dependence of the shear viscosities of PBAT and PLA

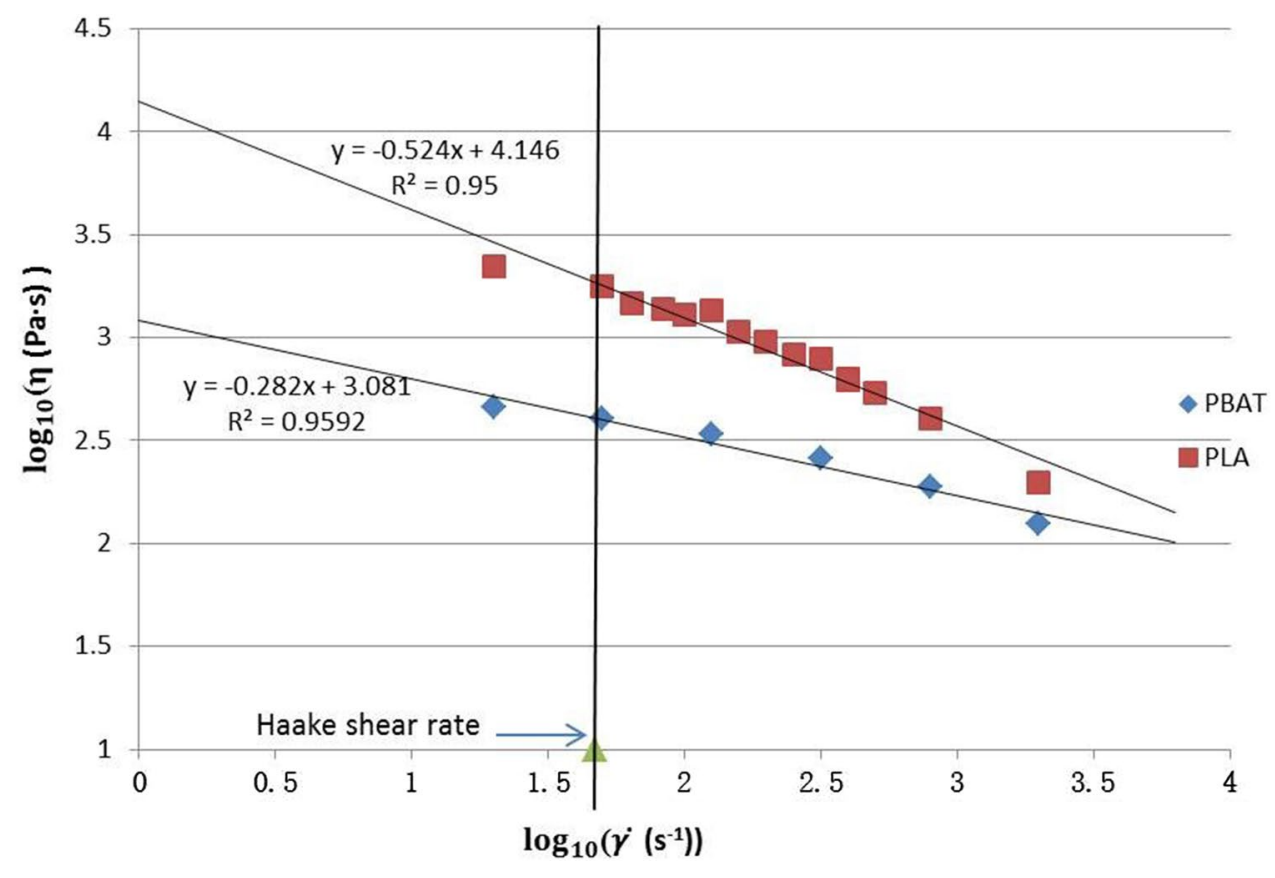


of $47 \mathrm{~s}^{-1}$ into the appropriate viscosity equations, the shear viscosities of PLA and PBAT were calculated to be 1859 and 406 Pa.s respectively.

These results show that the viscosity of PBAT is much lower than that of PLA at the processing conditions. The viscosity ratio of PBAT to PLA is 0.218 . According to Eq. (1), the ratio of the volume fractions of two polymers at which a co-continuous phase structure begins to form is determined by the ratio of their melt viscosities during processing. So when the value of $\varphi_{\mathrm{PBAT}} / \varphi_{\mathrm{PLA}}$ reaches 0.218 , a co-continuous phase should begin to form if Eq. (1) is valid in this case. Because the density of PBAT $\left(1.25 \mathrm{~g} \mathrm{~cm}^{-3}\right)$ and that of PLA $\left(1.25-1.27 \mathrm{~g} \mathrm{~cm}^{-3}\right)$ are almost same, the weight fraction of each component was regarded to be the same as its volume fraction. Hence, the critical value of $\varphi_{\mathrm{PBAT}}$ to form a cocontinuous phase is calculated to be $17.9 \mathrm{wt} \%$. Thus when the content of PBAT reaches $18 \mathrm{wt} \%$, a co-continuous phase structure should start to form and significant improvement in ductility would be expected.

A polynomial model can also be applied to predict the viscosity of PLA and PBAT, shown in Eq. (9). (Coefficients $\mathrm{A}_{0}, \mathrm{~A}_{1}$ and $\mathrm{A}_{2}$ are three material parameters.) (Fig. 4).

$\log \eta=A_{0}+A_{1} \log (\dot{\Upsilon})+A_{2} \log (\dot{\Upsilon})^{2}$

Comparing value of $\mathrm{R}^{2}$ in the Power law and Polynomial models, it can be seen that the Polynomial model gives a better fit. Substituting a shear strain rate of $47 \mathrm{~s}^{-1}$ into Eq. (9) gives the value of shear viscosity of 1760 and 413 Pa.s for PLA and PBS respectively, which gives a viscosity ratio of 0.235 . The critical value of $\varphi_{\mathrm{PBAT}}$ to form a co-continuous phase is calculated to be $19.0 \mathrm{wt} \%$. Since the Polynomial model gives a better fit to the viscosity data, the value of $19 \mathrm{wt} \%$ is taken as the more accurate prediction of the cocontinuous phase.

Lu et al. [31] also reported that viscosity ratio helps to determine the morphology of PBAT/PLA blends. They investigated PBAT/PLA blends at 30/70 w/w containing various amounts of dicumyl peroxide. They did not find a co-continuous phase structure, only a typical sea-island morphology. Another paper that investigated rheological properties of compatibilized PBAT/PLA blends (at 20/80 $\mathrm{w} / \mathrm{w}$ ) is that of Al-Itry et al. [32]. Reactive compatibilization was found to give improvement in mechanical properties through chain extension and copolymer formation but not a co-continuous phase morphology.

\section{Crystallinity and Thermal Properties}

DSC traces of PBAT/PLA blends are shown in Fig. 5. On heating from 20 to $180{ }^{\circ} \mathrm{C}$, PLA goes through the glass transition $\left(55 \pm 1.5^{\circ} \mathrm{C}\right)$, cold crystallization $\left(100 \pm 3{ }^{\circ} \mathrm{C}\right)$ and melting $\left(169 \pm 2{ }^{\circ} \mathrm{C}\right)$. The glass transition temperature of PBAT is $-30{ }^{\circ} \mathrm{C}$. PBAT is a random co-polymer and therefore does not have a sufficiently symmetrical structure to give high levels of crystallinity. However, there is a very broad and shallow endotherm around $100-120{ }^{\circ} \mathrm{C}$ indicating some crystallisation of PBAT.

DSC results show that the glass transition temperature $\left(\mathrm{T}_{\mathrm{g}}\right)$ of the blends barely changes regardless of the concentration of PBAT, which indicates that PBAT is not miscible with PLA. According to the rule of mixing, if the amorphous regions of the PBAT are miscible with the
Fig. 4 Shear strain rate dependence of the shear viscosities of PBAT and PLA; regression analysis with Polynomial model

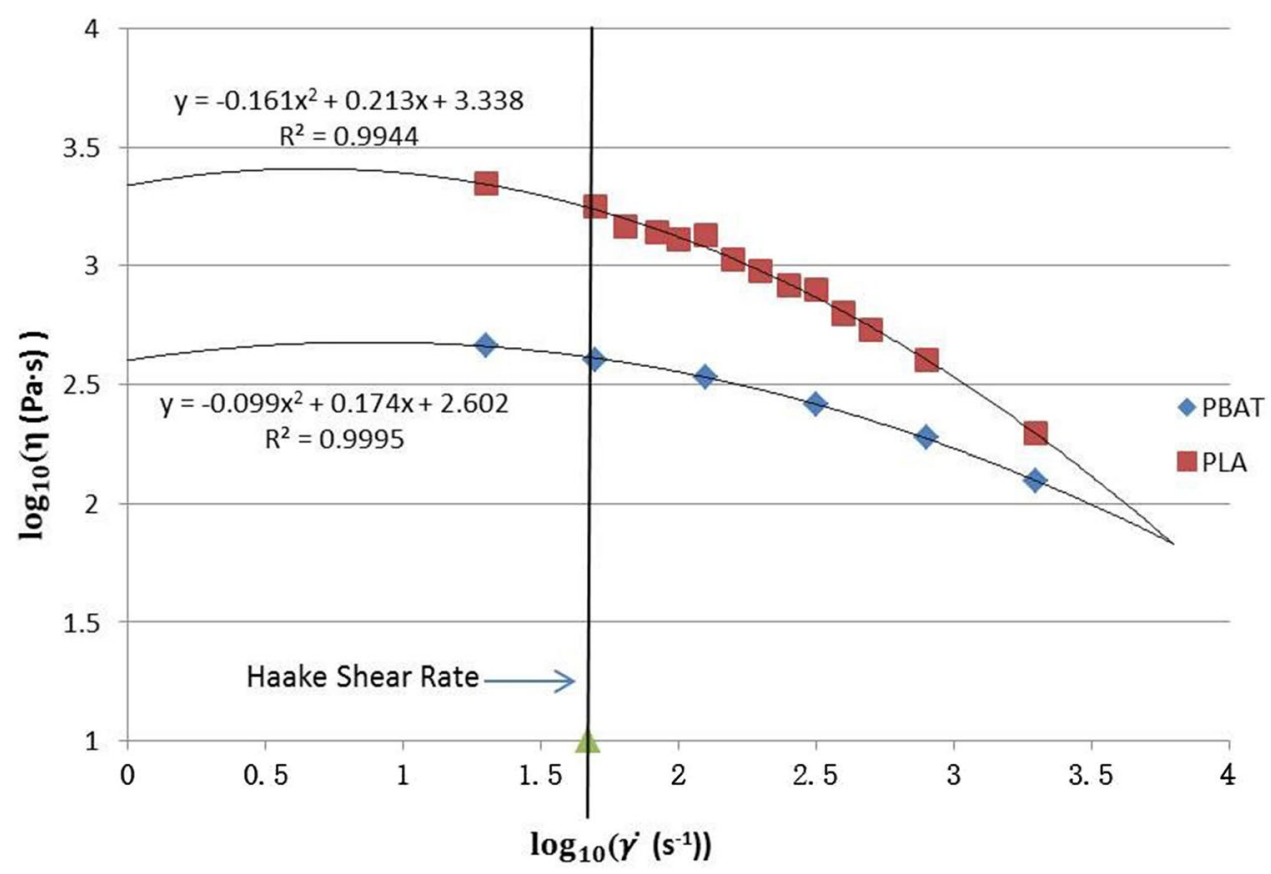




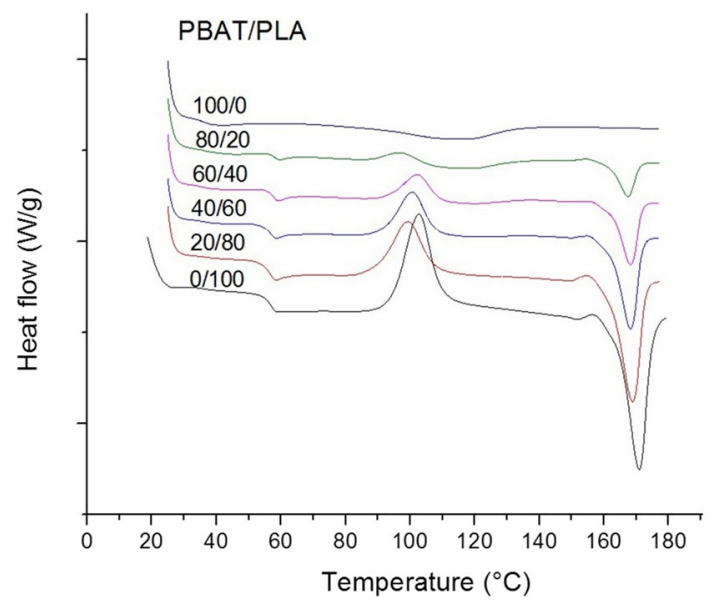

Fig. 5 DSC traces of PBAT/PLA blends

amorphous regions of the PLA, then there should be a shift in the glass transition temperature of the blend according to the Fox equation [33]:

$\frac{1}{T_{g}}=\frac{\omega(\mathrm{PBAT})}{T_{g}(\mathrm{PBAT})}+\frac{\omega(\mathrm{PLA})}{T_{g}(\mathrm{PLA})}$

In Eq. (10), $T_{\mathrm{g}}$ is the glass transition temperature of the blend in $\mathrm{K} ; T_{g}(P B A T)$ is the glass transition temperature of PBAT, which is $239 \mathrm{~K} ; T_{g}(P L A)$ is the glass transition temperature of PLA, which is $332 \mathrm{~K} ; \omega(P B A T)$ is the weight fraction of amorphous PBAT in the total amorphous region; $\omega(P L A)$ is the weight fraction of amorphous PLA in the total amorphous region. When PBAT is $20 \mathrm{wt} \%$, $\omega(P B A T)$ is $21.46 \%$ and $\omega(P L A)$ is $78.54 \%$. The measured and theoretical values of $T_{\mathrm{g}}$ are compared in Table 1. From these data it appears that PLA is not miscible with PBAT at any point above $20 \mathrm{wt} \%$ of PBAT.

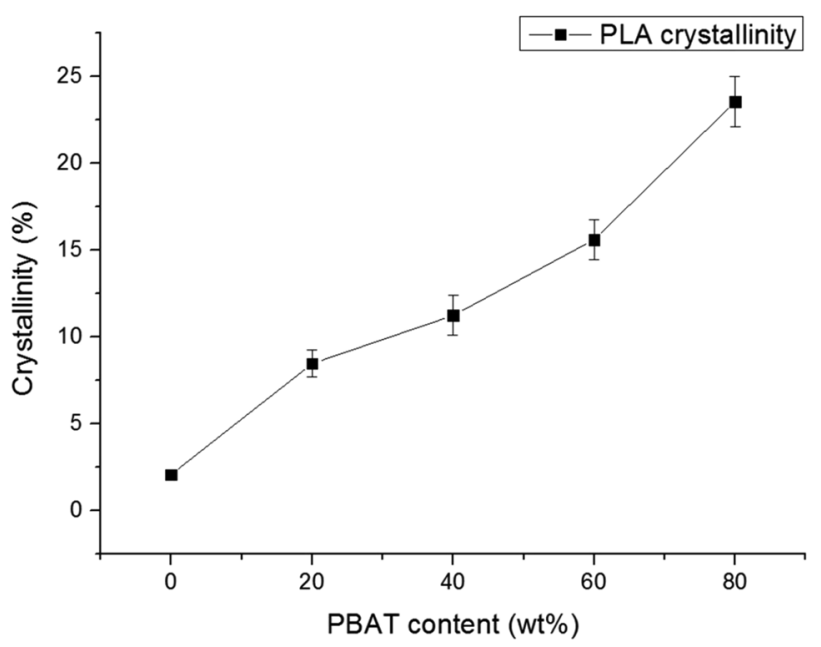

Fig. 6 Effect of PBAT content on PLA crystallinity

Crystallinity was also measured from the DSC traces. PBAT is not highly crystalline but from the very broad and shallow endotherm it was calculated that the degree of crystallinity of $100 \%$ PBAT was $8.8 \pm 0.7 \%$.

Results for the cold crystallisation temperature $\left(\mathrm{T}_{\mathrm{c}}\right)$ and enthalpy $\left(\Delta \mathrm{H}_{\mathrm{c}}\right)$, melting temperature $\left(\mathrm{T}_{\mathrm{m}}\right)$ and enthalpy $\left(\Delta \mathrm{H}_{\mathrm{m}}\right)$, and degree of crystallinity $\left(\% \mathrm{X}_{\mathrm{c}}\right)$ of PLA in the blends are summarised in Table 2. It is seen that the cold crystallisation temperature is slightly reduced, particularly for blends $20 / 80$ and $80 / 20$, implying that crystallisation of PLA is facilitated. Also, PLA is found to show a greater degree of crystallisation as the amount of PBAT in the formulation increased. This somewhat surprising result is plotted in Fig. 6. It implies that PBAT can act as a nucleating agent for crystallisation of PLA.

There are a number of studies that have reported on the crystallisation behaviour of PLA/PBAT blends. There are
Table 1 Glass transition temperature of PBAT/PLA blends

Table 2 Cold crystallisation, melting and crystallinity of PLA in PBAT/PLA blends

\begin{tabular}{llllll}
\hline PBAT $($ wt $\%)$ & 0 & 20 & 40 & 60 & 80 \\
\hline Measured $\mathrm{T}_{\mathrm{g}}\left({ }^{\circ} \mathrm{C}\right)$ & $55.8 \pm 1.8$ & $54.4 \pm 0.2$ & $54.8 \pm 0.3$ & $56.3 \pm 0.3$ & $56.6 \pm 0.2$ \\
Theoretical $\mathrm{T}_{\mathrm{g}}\left({ }^{\circ} \mathrm{C}\right)$ & N/A & 33.4 & 11.5 & -7.2 & -22.8 \\
\hline
\end{tabular}

\begin{tabular}{lrlrrr}
\hline $\begin{array}{l}\text { PBAT/PLA } \\
\text { blends }\end{array}$ & \multicolumn{1}{c}{$\mathrm{T}_{\mathrm{c}}\left({ }^{\circ} \mathrm{C}\right)$} & $\mathrm{T}_{\mathrm{m}}\left({ }^{\circ} \mathrm{C}\right)$ & $\Delta \mathrm{H}_{\mathrm{c}}(\mathrm{J} / \mathrm{g})$ & $\Delta \mathrm{H}_{\mathrm{m}}(\mathrm{J} / \mathrm{g})$ & \multicolumn{1}{c}{$\% \mathrm{X}_{\mathrm{c}}$} \\
\hline $0 / 100$ & $102.2 \pm 0.4$ & $170.8 \pm 0.4$ & $33.6 \pm 1.0$ & $35.1 \pm 1.0$ & $2.1 \pm 0.1$ \\
$20 / 80$ & $99.5 \pm 0.5$ & $169.0 \pm 0.3$ & $19.2 \pm 0.5$ & $25.6 \pm 0.1$ & $8.5 \pm 0.8$ \\
$40 / 60$ & $100.9 \pm 0.5$ & $168.7 \pm 0.5$ & $13.2 \pm 0.1$ & $19.5 \pm 0.6$ & $11.2 \pm 1.1$ \\
$60 / 40$ & $102.5 \pm 0.9$ & $168.7 \pm 0.7$ & $7.4 \pm 0.6$ & $13.3 \pm 0.9$ & $15.6 \pm 1.1$ \\
$80 / 20$ & $96.7 \pm 0.5$ & $167.7 \pm 0.2$ & $1.8 \pm 0.03$ & $6.2 \pm 0.3$ & $23.5 \pm 1.5$ \\
\hline
\end{tabular}


mixed results on whether PBAT increases or decreases the crystallinity of PLA. However, there does appear to be a consensus that PBAT increases the crystallisation rate of PLA. Yeh et al. [13] found that the percentage crystallinity of PLA in melt-compounded blends reduced gradually as the PBAT content increased. Chiu et al. [15] investigated heat treatment effects and obtained high levels of crystallinity but again reported a decrease in crystallinity of PLA with increasing PBAT content. Liu et al. [12] investigated the non-isothermal crystallisation kinetics of poly(L-lactide) PLLA/PBAT blends. They also reported that crystallinity of the PLLA-rich phase decreased with increasing PBAT content. However, they found that the crystallisation rate coefficients of the blend membranes were higher than those of the original PLLA, suggesting that amorphous domains of PBAT serve as effective nucleation sites for PLLA. In their study, Xiao et al. [17] observed that the degree of crystallinity of PLA in PLA/PBAT blends was markedly increased and there was found to be an increase in crystallisation rate with increase in PBAT content. Jiang et al. [16] investigated recrystallization of both neat PLA and a PLA-5\% PBAT blend. They found that the blend started to crystallise at a lower temperature than the neat PLA, suggesting the presence of a new crystalline structure induced by PBAT.

Our results verify that the degree of crystallization of PLA increases with increasing content of PBAT, implying that PBAT serves as nucleation sites for PLA crystallization.

\section{Optical Microscopy}

Optical microscopy was used to study the phase structure of the blends. The images for bright field illumination are shown in Fig. 7.

From the bright field micrographs in Fig. 7, it is seen that there is phase separation in all six of the PBAT/PLA blends shown. The two phases will either be continuously interdispersed in the form of a 3D network or will be present as discrete spherical domains embedded in a surrounding matrix, which is often described as a sea-island structure.

The sample at the composition of 20/80 PBAT/PLA has a fine structure with the PBAT well dispersed in the PLA. From the viscosity ratio calculation, it was predicted that a co-continuous phase structure should be formed at a PBAT concentration of $19 \mathrm{wt} \%$. The optical micrograph of the $20 / 80$ composition is typical of that of two interpenetrating phases [34], thereby giving credence to the co-continuous phase prediction. The morphologies of the 30/70 and 40/60 blends are also typical of co-continuous phase structures. At the 40/60 composition ratio, the structure has started to coarsen with distinct droplets being visible, although the cocontinuous phase structure is still evident inside the droplets. This coarsening of the structure implies that the $40 / 60$ blend is near the upper limit of the co-continuous range.
The other three compositions in Fig. 7 all show sea-island morphologies. The structure of the $10 / 90$ blend has small spheres of PBAT, around $1 \mu \mathrm{m}$ in size, in a matrix of PLA. The PBAT spherical domains are small because the melt viscosity of PBAT is much less than that of PLA and so the PBAT is easily broken down in the melt into small droplets. At the 60/40 composition ratio PBAT has become the sole continuous phase with droplets of PLA of diverse sizes (20-40 $\mu \mathrm{m})$ within the PBAT matrix. The reason for the large droplets of PLA in the PBAT matrix is because of the difference in melt viscosities of the two polymers. Due to their high melt viscosity, PLA droplets will not become easily broken down and dispersed in the PBAT matrix. However, for the 80/20 sample, there is a finer structure because at the much higher PBAT/PLA concentration ratio, the PLA droplets break up much more readily.

\section{Mechanical Properties}

\section{Tensile Test Results}

Tensile testing was used to determine the mechanical properties of PBAT/PLA blends and to look for evidence of co-continuous phase formation. There was expected to be enhanced ductility of the blends in a region of dual phase continuity.

The results of Young's modulus and tensile strength of the various blends are plotted as a function of PBAT content in Figs. 8 and 9 respectively. Both Young's modulus and tensile strength decrease with increasing PBAT content. This result was not unexpected on adding increasing levels of a soft, flexible material to a hard, rigid one.

Two models that are often used to predict the behaviour of composites or blends are the Parallel and Series models, written for modulus in Eqs. (11) and (12).

Parallel Model $E_{b}=\varphi_{1} E_{1}+\varphi_{2} E_{2}$

Series Model $E_{b}=\frac{E_{1} E_{2}}{\left(\varphi_{1} E_{2}+\varphi_{2} E_{1}\right)}$

In these equations $E_{1}$ and $E_{2}$ are the moduli of components 1 and 2 respectively, while $E_{b}$ is the modulus of the blend. $\varphi_{1}$ and $\varphi_{2}$ are the volume fractions of components 1 and 2 . These two models represent the upper and lower predicted boundaries of behaviour. The Parallel model assumes that the continuous phase consists of the higher modulus polymer and therefore represents the upper boundary, whereas the lower boundary is represented by the Series model, which assumes that the lower modulus component is the continuous phase. In this case the higher modulus polymer is PLA (1672 MPa) and the lower modulus polymer is PBAT (50 MPa). 


\section{PBAT/PLA Blends}
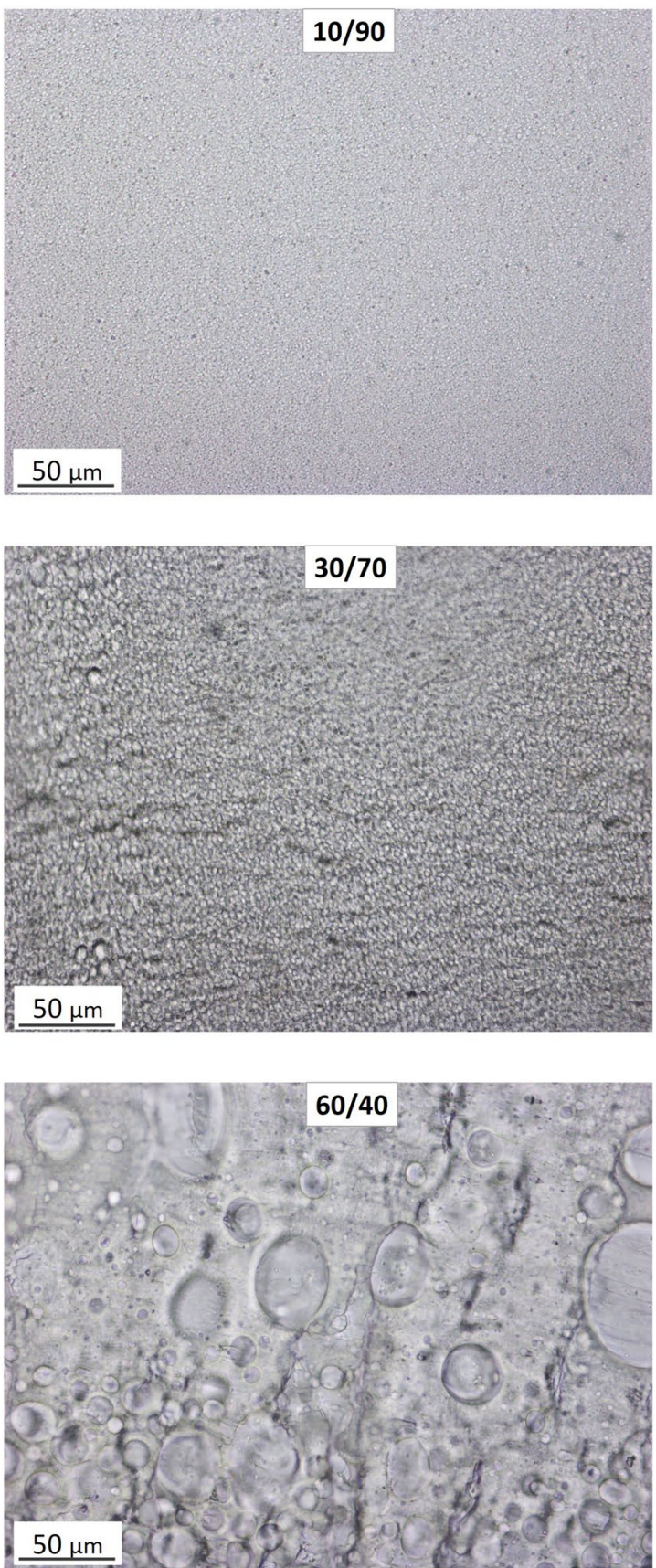

Fig. 7 Optical micrographs of PBAT/PLA blends-bright field

The Young's moduli of all the blends fall into the range between the Parallel and Series models, suggesting that PBAT and PLA are compatible even though they are not miscible. Up to $40 \mathrm{wt} \%$ of PBAT, the blend modulus tracks the Parallel model, which indicates that PLA is acting as a continuous (or co-continuous phase). However it is interesting to see that when the PBAT content increases above $40 \mathrm{wt} \%$, there is a dramatic decrease in Young's modulus.
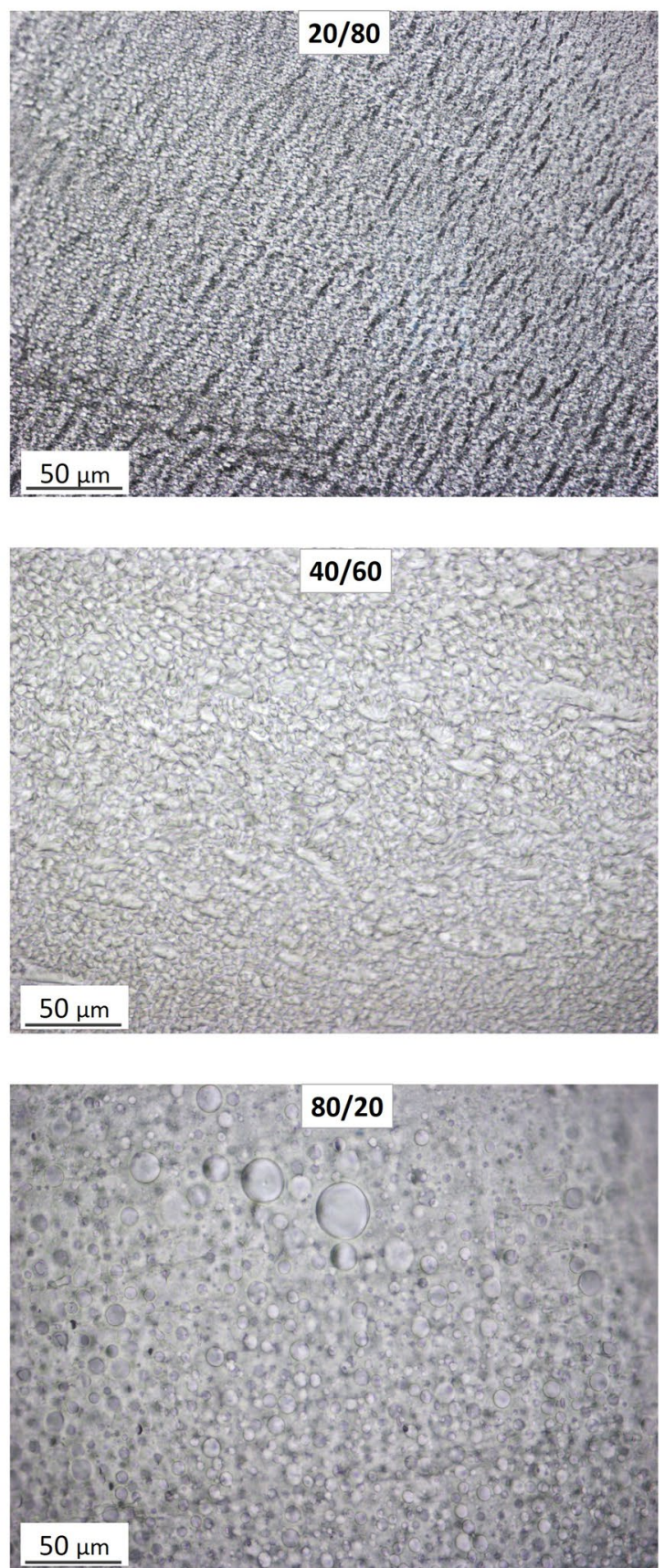

Between 50 and $100 \mathrm{wt} \%$ of PBAT, Young's modulus data are tracking the Series model. This indicates that from $50 \mathrm{wt} \%$ and above, PBAT is the continuous phase with PLA dispersed within it. The dramatic drop in modulus from $1000 \mathrm{MPa}$ at $40 \mathrm{wt} \%$ PBAT to about $400 \mathrm{MPa}$ at $50 \mathrm{wt} \%$ PBAT indicates that the upper limit of the cocontinuous range falls between 40 and $50 \mathrm{wt} \%$ of PBAT. 


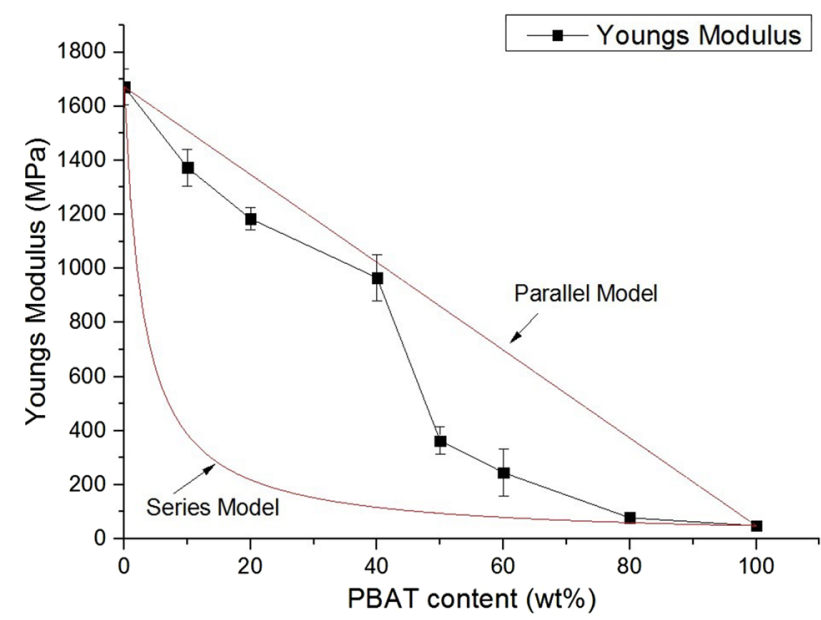

Fig. 8 The effect of PBAT content on Young's modulus

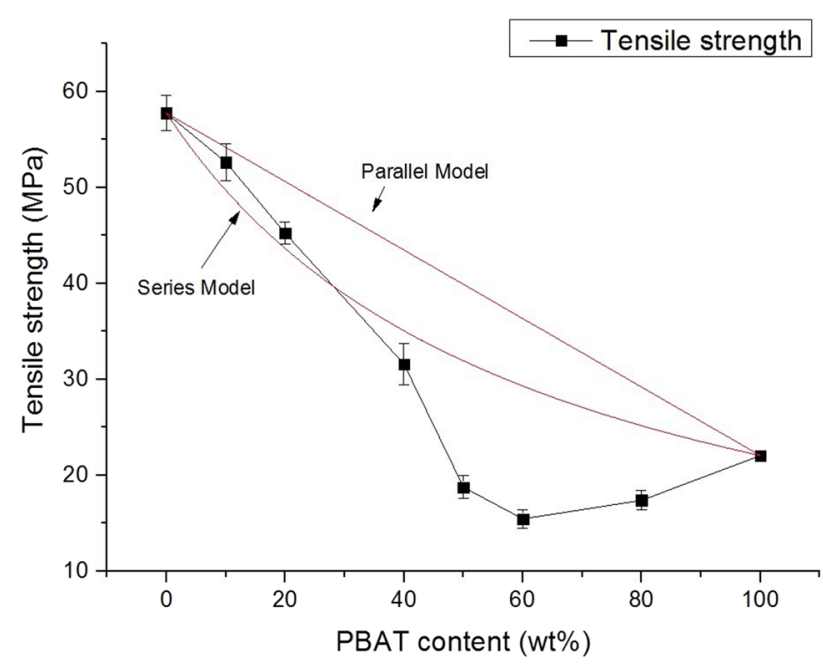

Fig. 9 The effect of PBAT content on tensile strength

In Fig. 9 it is seen that tensile strength drops below the lower boundary when the PBAT content increases above $30 \mathrm{wt} \%$. There is a very steep drop in tensile strength between 40 and $50 \mathrm{wt} \%$. This confirms a very significant change in morphology in this region with PBAT becoming the continuous phase and with poor interaction between the phases.

The results of elongation-at-break are plotted as a function of PBAT content in Fig. 10, which shows a very significant increase (from around 10\% up to 300\%) in the composition range between 10 and $20 \mathrm{wt} \%$ PBAT. This improvement is evidence that a co-continuous phase structure has been formed in this composition range. Elongation-at-break remains above $300 \%$ in the composition range from 20 to $40 \mathrm{wt} \%$ PBAT but then drops back down to around $100 \%$ at the composition of $50 \mathrm{wt} \%$. This drop in elongation-at-break

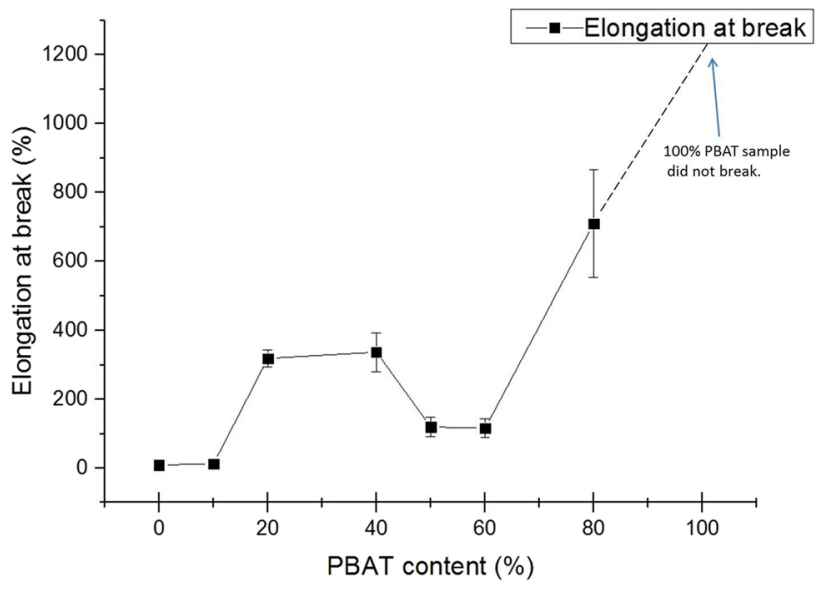

Fig. 10 Effect of PBAT content on elongation-at-break

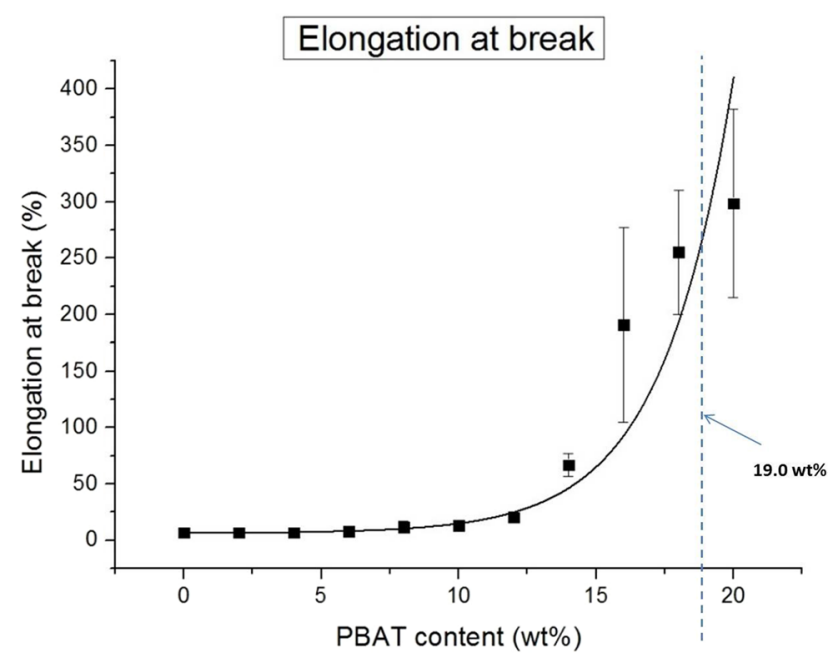

Fig. 11 Elongation at break of PBAT/PLA blends when PBAT content ranges from 0 to $20 \mathrm{wt} \%$

between 40 and $50 \mathrm{wt} \%$ of PBAT marks the upper limit of the co-continuous phase structure i.e. the co-continuous phase is replaced by another structure, which is that of large PLA particles dispersed in a PBAT matrix, as shown in the optical micrographs (Fig. 6) and discussed below for the SEM images of the fracture surfaces. However, when the PBAT content is increased above $60 \mathrm{wt} \%$, the ductility increases further. This is because pure PBAT is very ductile and when the PBAT content reaches $80 \mathrm{wt} \%$, the droplets of PLA have become very fine and well dispersed, so the negative effect on elongation-at-break is compensated for by the higher PBAT concentration.

The establishment of a co-continuous phase at a low concentration of PBAT was further investigated by studying blends with compositions at $2 \mathrm{wt} \%$ increments of PBAT between 0 and $20 \mathrm{wt} \%$. The results of 
elongation-to-break tests are plotted in Fig. 11. It is clearly seen that below $14 \mathrm{wt} \%$, ductility is very poor, implying that PBAT particles are dispersed in a PLA matrix phase. However, between 16 and $19 \mathrm{wt} \%$, elongation-at-break starts to increase significantly and there is a large standard deviation in the data. This indicates that at around $18 \mathrm{wt} \%$ of PBAT, a co-continuous phase structure starts to form. Hence some specimens have a very high ductility because they have a well-developed co-continuous phase structure, whereas others are more brittle because the co-continuous phase structure is incomplete. This result strongly confirms the predicted value from the empirical viscosity model discussed in see "Melt Rheology" section, i.e. that the critical value of PBAT to form a co-continuous phase structure is calculated to be $19 \mathrm{wt} \%$ and when the content of PBAT reaches this value a significant improvement in ductility is expected.
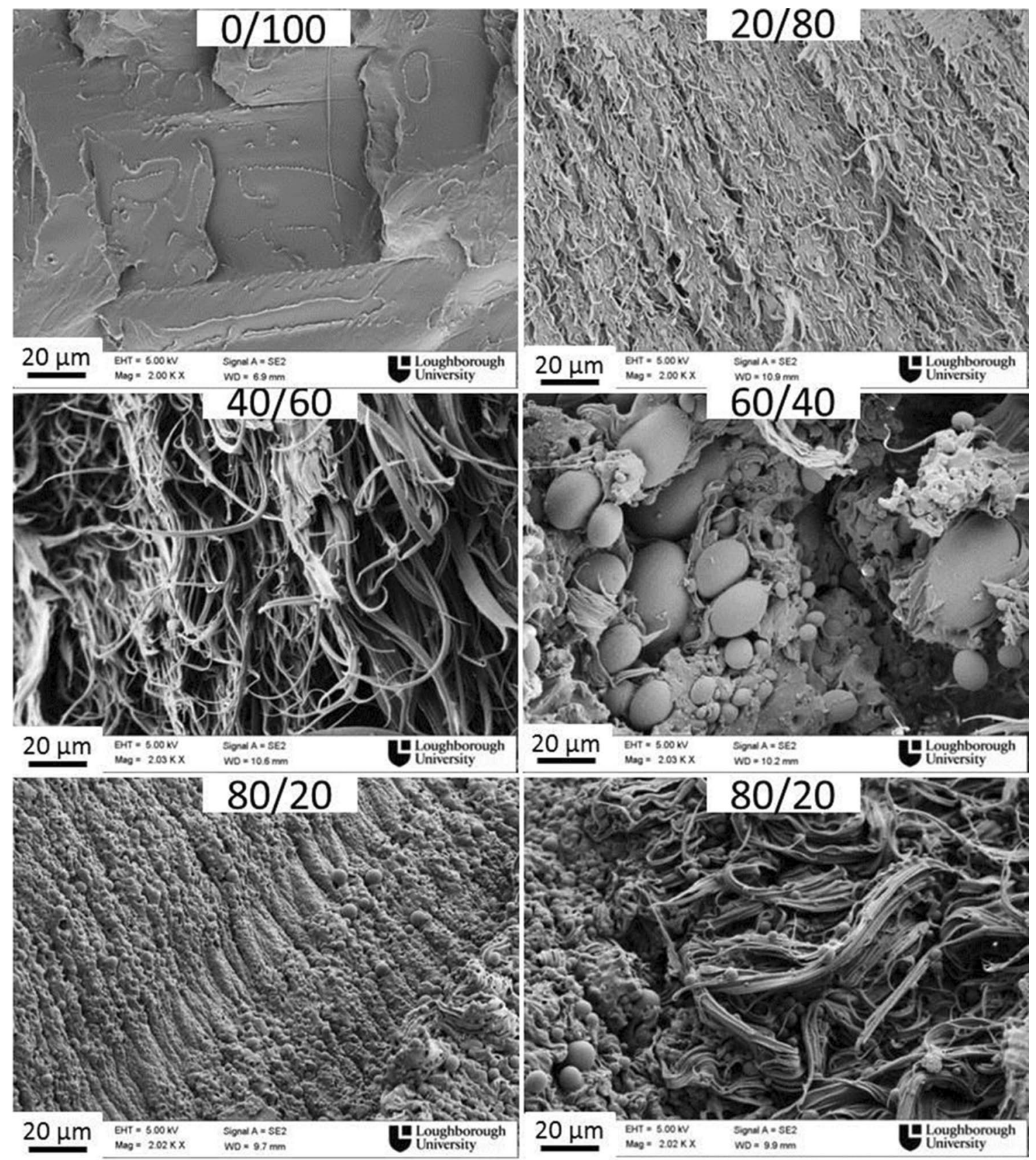

Fig. 12 Scanning electron micrographs of fracture surfaces of PBAT/PLA blends 


\section{Scanning Electron Microscopy of Fracture Surfaces}

To analyse the morphology of the PBAT/PLA blends further, Scanning Electron Microscopy was used. The SEM images of PBAT/PLA blend fracture surfaces from the tensile tests are shown in Fig. 12. The fracture surface for pure PLA shows a flat, featureless structure that is typical of a brittle fracture surface. For 20 and $40 \mathrm{wt} \%$ of PBAT, the fracture surfaces show that fibrils have been drawn from the surface, which is a common feature of ductile failure. These micrographs indicate that PBAT and PLA have a co-continuous phase structure at compositions of PBAT between 20 and $40 \mathrm{wt} \%$. It is expected that these fibrils are due to the PBAT continuous phase because PBAT has a much lower yield stress than PLA and will undergo plastic deformation at lower stress.

When the PBAT content has reached $60 \mathrm{wt} \%$, it is clear that now the PLA continuous phase has disappeared. It is seen from the 60/40 sample that PLA is present as large particles dispersed within the PBAT continuous phase. These large PLA particles become debonded from the PBAT matrix and so cracks and flaws will be induced at the interface, resulting in relatively poor mechanical properties. This accounts for the dramatic decreases in both modulus (Fig. 8) and tensile strength (Fig. 9) between 40 and $60 \mathrm{wt} \%$ PBAT. It also accounts for the unexpected drop in ductility observed in the same composition range (Fig. 10). A dramatic drop in elongation-at-break with increasing PBAT content has also been found by other authors [35] although there was no explanation of the cause. When the PBAT content reaches $80 \mathrm{wt} \%$, it is seen from Fig. 10 that the samples show very ductile behaviour in the tensile test. The SEM image shows that PLA is still dispersed in the PBAT in the form of particles. However, the size of the particles has become much finer and the dispersion has become much more uniform. Therefore, at this point, the influence of PLA on the mechanical properties is very much diminished, and the blend performs in a similar way to PBAT.

To further investigate the co-continuous morphology in the blends, the acetone etched PBAT/PLA blends were investigated using SEM (Fig. 13). When the PBAT content is only $20 \mathrm{wt} \%$, a continuous network of PBAT remains after the PLA has been dissolved. The structure consists of a fragile PBAT skeleton with interconnected voids from where the PLA has been removed.

At $40 \mathrm{wt} \%$ of PBAT, there is still a co-continuous phase structure with a PBAT network interconnected with less voids. When the PBAT content reaches $50 \mathrm{wt} \%$, it is seen that PBAT is the only continuous phase and droplets of PLA have been dissolved. Hence the upper limit of the co-continuous structure lies in the range between 40 and $50 \mathrm{wt} \%$ of PBAT in agreement with what was predicted from the mechanical properties. Also for 60 and $80 \mathrm{wt} \%$ of PBAT, there are droplets of PLA in a PBAT matrix and their number and size reduces as the PLA content reduces.

\section{Melt Viscosity and Co-continuous Phase Structure}

The viscosity ratio of the two polymers during melt blending is a key factor in determining the morphology of the blends. In this study the results of capillary rheometry experiments (see "Melt Rheology" section) show that at the temperature and shear strain rate (i.e. $175{ }^{\circ} \mathrm{C}$ and $47 \mathrm{~s}^{-1}$ ) at which the PBAT and PLA were processed in the Haake mixer, their melt viscosities were 413 and 1760 Pa.s respectively. From Eq. (1) the composition ratio at which a co-continuous phase morphology is formed can be calculated, and so for this system the composition ratio is 0.235 [Eq. (13)].

$\frac{\varphi_{P B A T}}{\varphi_{P L A}}=\frac{\eta_{P B A T}}{\eta_{P L A}}=\frac{413}{1760}=0.235$

This corresponds to $19.0 \mathrm{wt} \%$ of PBAT in the formulation.

As shown in Fig. 11 and discussed above, this composition corresponds to where there is a very significant improvement in ductility as shown by the increase in elongation-at-break. This is advantageous because it predicts that relatively low additions of the low viscosity polymer will give large benefits in terms of enhanced ductility.

Figure 14 is a schematic diagram showing the phase morphologies of the PBAT/PLA blends over the full range of compositions, as deduced from the melt viscosities, optical micrographs, tensile properties and SEM fracture surfaces. The lower viscosity component, PBAT, is observed to form a continuous phase over a larger composition range than PLA.

\section{Conclusions}

The synergistic effects of melt blending two biodegradable polymers, poly(lactic acid) and poly(butylene adipate-coterephthalate), have been investigated. A range of melt blended compounds were prepared at various PBAT/PLA weight ratios of 0/100, 20/80, 40/60, 60/40, 80/20 and 100/0. Melt viscosities, thermal properties, crystallinity, mechanical properties and phase morphology were studied.

In particular it was the aim of this study to investigate whether PBAT/PLA blends can form a co-continuous phase structure and to predict the conditions under which this would occur. Capillary rheometry experiments were carried out at $175{ }^{\circ} \mathrm{C}$ to measure the melt viscosities of PLA and PBAT. Data at six different volumetric flow rates were fitted to a Power Law model. It was calculated that the shear rate at which the blends were mixed in the Haake mixer was $47 \mathrm{~s}^{-1}$ and at this shear rate the viscosities of PBAT and PLA were found to be 413 and $1760 \mathrm{~Pa}$.s respectively. The viscosity ratio of the polymers is reported to be equal to the ratio of 
Fig. 13 Scanning electron micrographs of PBAT/PLA blends after etching with acetone
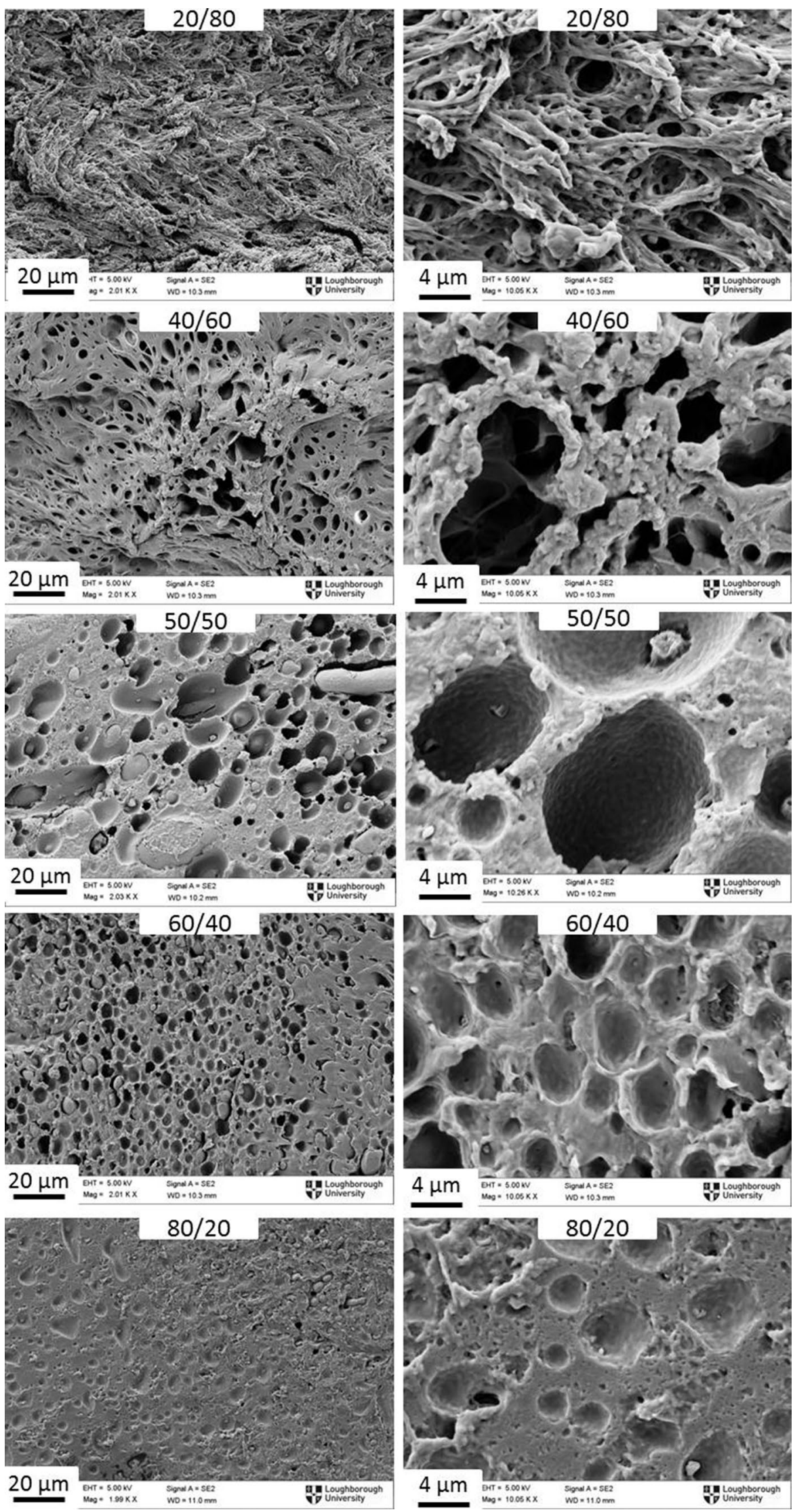


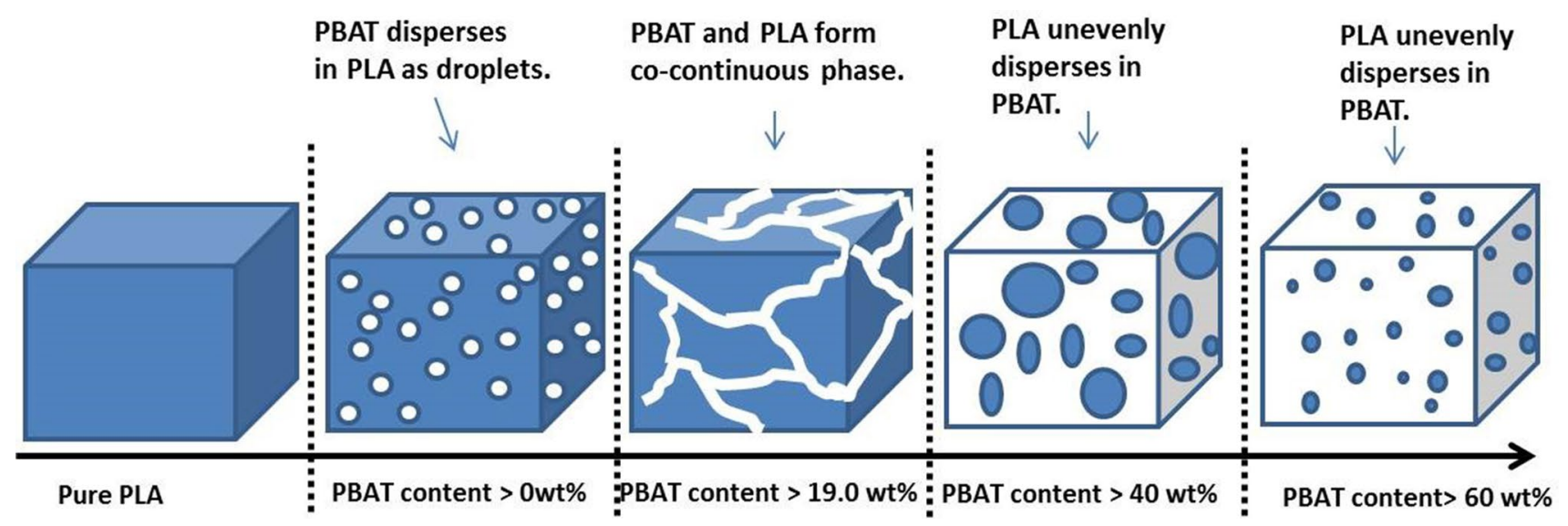

Fig. 14 Schematic diagram of phase structure as a function of composition

the volume fractions at which a co-continuous phase can be formed. Using this relationship, it was calculated that the threshold value for the formation of a co-continuous phase structure was $\varphi_{\mathrm{PBAT}} / \varphi_{P L A}$ equals 0.235 , which corresponds to a concentration of PBAT of $19 \mathrm{wt} \%$.

This result was borne out by the mechanical properties, where results for elongation-to-break showed a dramatic rise from around $10 \%$ up to $300 \%$ in the composition range between 10 and $20 \mathrm{wt} \%$ of PBAT. The co-continuous phase structure at $20 \mathrm{wt} \%$ PBAT was also validated by scanning electron micrographs. This study confirms that control of the viscosity ratio through the processing parameters of shear rate and temperature can be used to control the formation of two continuous phases to produce an interpenetrating network structure, with an associated unique combination of properties.

Acknowledgements The authors would like to acknowledge technical assistance from the following staff from the Department of Materials, Loughborough University: Dr Keith Yendall for scanning electron microscopy (SEM), and Mr Shaun Fowler and Dr Carole Raymond for optical microscopy.

Funding The authors are also grateful for funding for this work from the Department of Materials, Loughborough University, UK.

Open Access This article is distributed under the terms of the Creative Commons Attribution 4.0 International License (http://creativeco mmons.org/licenses/by/4.0/), which permits unrestricted use, distribution, and reproduction in any medium, provided you give appropriate credit to the original author(s) and the source, provide a link to the Creative Commons license, and indicate if changes were made.

\section{References}

1. Song JH, Murphy RJ, Narayan R, Davies GBH (2009) Biodegradable and compostable alternatives to conventional plastics. Phil Trans R Soc B 364:2127-2139
2. Vroman I, Tighzert L (2009) Biodegradable polymers. Materials 2:307-344

3. Amass WA, Tighe B (1998) A review of biodegradable polymers: uses, current developments in the synthesis and characterization of biodegradable polyesters, blends of biodegradable polymers and recent advances in biodegradation studies. Polym Int 47(2):89-144

4. Auras R, Harte B, Selke S (2004) An overview of polylactides as packaging materials. Macromol Biosci 4(9):835-864

5. Garlotta D (2002) A literature review of poly (lactic acid). Polym Environ 9:63-84

6. Liu H, Zhang J (2011) Research progress in toughening modification poly (lactic acid). J Polym Sci Part B 49(15):1051-1083

7. Imre B, Pukánszky B (2013) Compatibilization in bio-based and biodegradable polymer blends. Eur Polym J 49(6):1215-1233

8. Herrera R, Franco L, Rodriguez-Galan A, Puiggali J (2002) Characterization and degradation behaviour of poly(butylene adipate-co-terephthalate)s. J Polym Sci Part A 40(23):4141-4157

9. Zhang M, Diao X, Jin Y, Weng Y (2016) Preparation and characterization of biodegradable blends of poly (3-hydroxybutyrate-co-3- hydroxyhexanoate) and poly (butylene adipate-coterephthalate). J Polym Eng 36(5):473-480

10. Gu S-Y, Zhang K, Ren J, Zhan H (2008) Melt rheology of polylactide/poly(butylene adipate-co-terephthalate) blends. Carbohydr Polym 74:79-85

11. Zhang M, Thomas NL (2011) Blending polylactic acid (PLA) with polyhydroxybutyrate (PHB): the effect on thermal, mechanical and biodegradation properties. Adv Polym Technol 30(2):67-79

12. Liu TY, Lin WC, Yang MC, Chen SY (2005) Miscibility, thermal characterization and crystallization of poly(l-lactide) and poly(tetramethylene adipate-co-terephthalate) blend membranes. Polymer 46:12586-12594

13. Yeh J-T, Tsou C-H, Huang C-Y, Chen K-N, Wu C-S, Chai W-L (2010) Compatible and crystallization properties of poly(lactic acid)/poly(butylene adipate-co-terephthalate) blends. J Appl Poly Sci 116:680-687

14. Farsetti S, Cioni B, Lazzeri A (2011) Physico-mechanical properties of biodegradable rubber toughened polymers. Macromol Symp 301(1):82-89

15. Chiu H-T, Huang S-Y, Chen Y-F, Kuo M-T, Chiang T-Y, Chang C-Y, Wang Y-H (2013) Heat treatment effects on the mechanical properties and morphologies of poly(lactic acid)/poly (butylene 
adipate-co-terephthalate) blends. Int J Polym Sci. https://doi. org/10.1155/2013/951696

16. Jiang L, Wolcott MP, Zhang JW (2006) Study of biodegradable polylactide/poly(butylene adipate-co-terephthalate). Blends Biomacromol 7:199-207

17. Xiao H, Lu W, Yeh J-T (2009) Crystallization behavior of fully biodegradable poly(lactic acid)/poly(butylene adipate-co-terephthalate) blends. J Appl Poly Sci 112:3754-3763

18. Li K, Peng J, Turng L-S, Huang H-X (2011) Dynamic rheological behavior and morphology of polylactide/poly(butylenes adipateco-terephthalate) blends with various composition ratios. Adv Polym Technol 30(2):150-157

19. Paul DR (1985) Polymer blends: phase behaviour and property relationships. In: Paul DR, Sperling LH (eds) Multicomponent polymer materials, advances in chemistry. American Chemical Society, Washington.

20. Tol RT, Groeninckx G, Vinckier I, Moldenaers P, Mewis J (2004) Phase morphology and stability of co-continuous (PPE/PS)/PA6 and PS/PA6 blends: effect of rheology and reactive compatibilization. Polymer 45:2587-2601

21. Paul DR, Barlow JW (1980) Polymer blends. J Macromol Sci Part C 18(1):109

22. Jordhamo GM, Manson JA, Sperling LH (1986) Phase continuity and inversion in polymer blends and simultaneous interpenetrating networks. Polym Eng Sci 26(8):517-524

23. Metelkin VI, Blekht VS (1984) Formation of a continuous phase in heterogenous polymer mixtures. Colloid J USSR 46: 425-429

24. Han M, Seo W, Paik H, Hyun J, Lee J, Kim W (2003) Rheological properties and phase inversion of polypropylene and poly (styrene-co-acrylonitrile) blends. Polym J 35(2):127-132
25. Willemse RC, Posthuma de Boer A, Van Dam J, Gotsis AD (1998) Co-continuous morphologies in polymer blends: a new model. Polymer 39(24):5879-5887

26. Wu D, Zhang Y, Zhang M, Zhou W (2008) Phase behavior and its viscoelastic response of polylactide/poly( $\varepsilon$-caprolactone) blend. Eur Polym J 44:2171-2183

27. Deng Y, Thomas NL (2015) Blending poly(butylene succinate) with poly(lactic acid): ductility and phase inversion effects. Eur Polymer J 71:534-546

28. Barton AFM (1983) Handbook of solubility parameters and other cohesion parameters. CRC Press, Boca Raton

29. Galloway JA, Macosko CW (2004) Comparison of methods for the detection of cocontinuity in poly(ethylene oxide)/polystyrene blends. Polym Eng Sci 44(4):714-727

30. Bousmina M, Ait-kadi A, Faisant JB (1999) Determination of shear rate and viscosity from batch mixer data. J Rheol 43(2):415

31. Lu X, Zhao J, Yang X, Xiao P (2017) Morphology and properties of biodegradable poly(lactic acid)/poly(butylene adipate-coterephthalate) blends with different viscosity ratio. Polym Test 60:58-67

32. Al-Itry R, Lamnawar K, Maazouz A (2014) Rheological, morphological, and interfacial properties of compatibilized PLA/PBAT blends. Rheol Acta 53(7):501-517

33. Brostow W, Chiu R, Kalogeras IM, Vassilikou-Dova A (2008) Prediction of glass transition temperatures: binary blends and copolymers. Mater Lett 62(17-18):3152-3155

34. Mascia L (1989) Thermoplastics: materials engineering, 2nd edn. Elsevier, London

35. Zhao P, Liu W, Wu Q, Ren J (2010) Preparation, mechanical, and thermal properties of biodegradable polyesters/poly(lactic acid) blends. J Nanomater. 2010:4

\section{Affiliations}

\section{Yixin Deng ${ }^{1} \cdot$ Changyi Yu ${ }^{1}$ Peangpatu Wongwiwattana ${ }^{1} \cdot$ Noreen L. Thomas $^{1}$}

Noreen L. Thomas

N.L.Thomas@lboro.ac.uk
Department of Materials, Loughborough University, Ashby Road, Loughborough, Leicestershire LE11 3TU, UK 